\title{
Control Strategy for PHEB Based on Actual Driving Cycle with Driving Style Characteristic
}

\author{
Jianping Gao, ${ }^{1,2}$ Zhenhai Xu ${ }^{1}{ }^{1}$ and Xiaojie Gao $\mathbb{i D}^{3}$ \\ ${ }^{1}$ Vehicle \& Transportation Engineering Institute, Henan University of Science and Technology, Luoyang 471003, China \\ ${ }^{2}$ Collaborative Innovation Center of Machinery Equipment Advanced Manufacturing of Henan, Luoyang 471003, China \\ ${ }^{3}$ Suzhou Automotive Research Institute, Tsinghua University, Suzhou 215200, China
}

Correspondence should be addressed to Zhenhai Xu; 160303360142@stu.haust.edu.cn

Received 7 October 2018; Revised 29 March 2019; Accepted 10 April 2019; Published 2 May 2019

Academic Editor: Carlos-Andrés García

Copyright (C) 2019 Jianping Gao et al. This is an open access article distributed under the Creative Commons Attribution License, which permits unrestricted use, distribution, and reproduction in any medium, provided the original work is properly cited.

\begin{abstract}
To exert fully the energy economy performance of plug-in hybrid electric buses (PHEBs) and enhance the adaptability to different drivers and driving cycles, a control strategy for PHEB based on actual driving cycle with driving style characteristic is proposed in this paper. Through the actual city bus driving data, collected in real time, 6 actual driving cycles with driving style characteristic are fitted by using Principal Component Analysis (PCA) and Cluster Analysis (CA). Based on the 6 driving cycles, the key parameters of rule-based control strategy are optimized and established by a combinatorial optimization algorithm in Isight. Then, an identification model to recognize the current condition based on the Learning Vector Quantization (LVQ) neural network has been built and trained offline, which is integrated in the control strategy for PHEB to invoke the corresponding optimized key control parameters in real time. A hardware-in-the-loop (HIL) test is conducted, and the result shows that the proposed strategy could improve the energy consumption by $4.94 \%$, compared with the original rule-based control strategy, and its validity and practicability are fully verified.
\end{abstract}

\section{Introduction}

Internal combustion engine (ICE) and electric machine (EM) are collectively used as the power sources of PHEB by electromechanical coupling system, which makes PHEB acquire more superior economy and emission performance compared with hybrid electric bus (HEB), and wider driving range and better environment adaptability compared with electric bus (EB). But, on account of the diversity of power sources, the complexity of electromechanical coupling system, and the variety of road driving cycles, there are some challenges for PHEB energy meticulous management $[1,2]$.

At present, the PHEB strategies mainly include rulebased and optimization-based strategies, where the former include the strategies based on deterministic rules and fuzzy rules, and the latter include global optimization strategies based on dynamic programming (DP), etc., and real-time optimization strategies based on model predictive control
(MPC), etc. [3, 4]. In [5], the rule-based strategy was used to allocate the output between the hybrid energy storage system (HESS) and the assistance power unit (APU), and the MPC was introduced to regulate the output between the battery and the ultracapacitor. Reference [6] predicted the electric power demand by the state transition probability matrices of the electrical power with different speeds, and the result was that the overall loss incurred by the whole HESS is reduced. Although the above control strategies have obtained some certain positive results, they rely on the standard driving cycles too much, resulting in a certain deviation with actual driving scenes. What is more, there are some studies which focus on the drivers' driving behaviors when developing the strategies. For example, the demanding torque correction factor was adjusted to meet different driving intentions in [7]. In [8], the driver behaviors were regarded as stochastic disturbance inputs, and the stochastic MPC was modified with the equivalent consumption minimization strategy (ECMS). However, these control strategies do not 


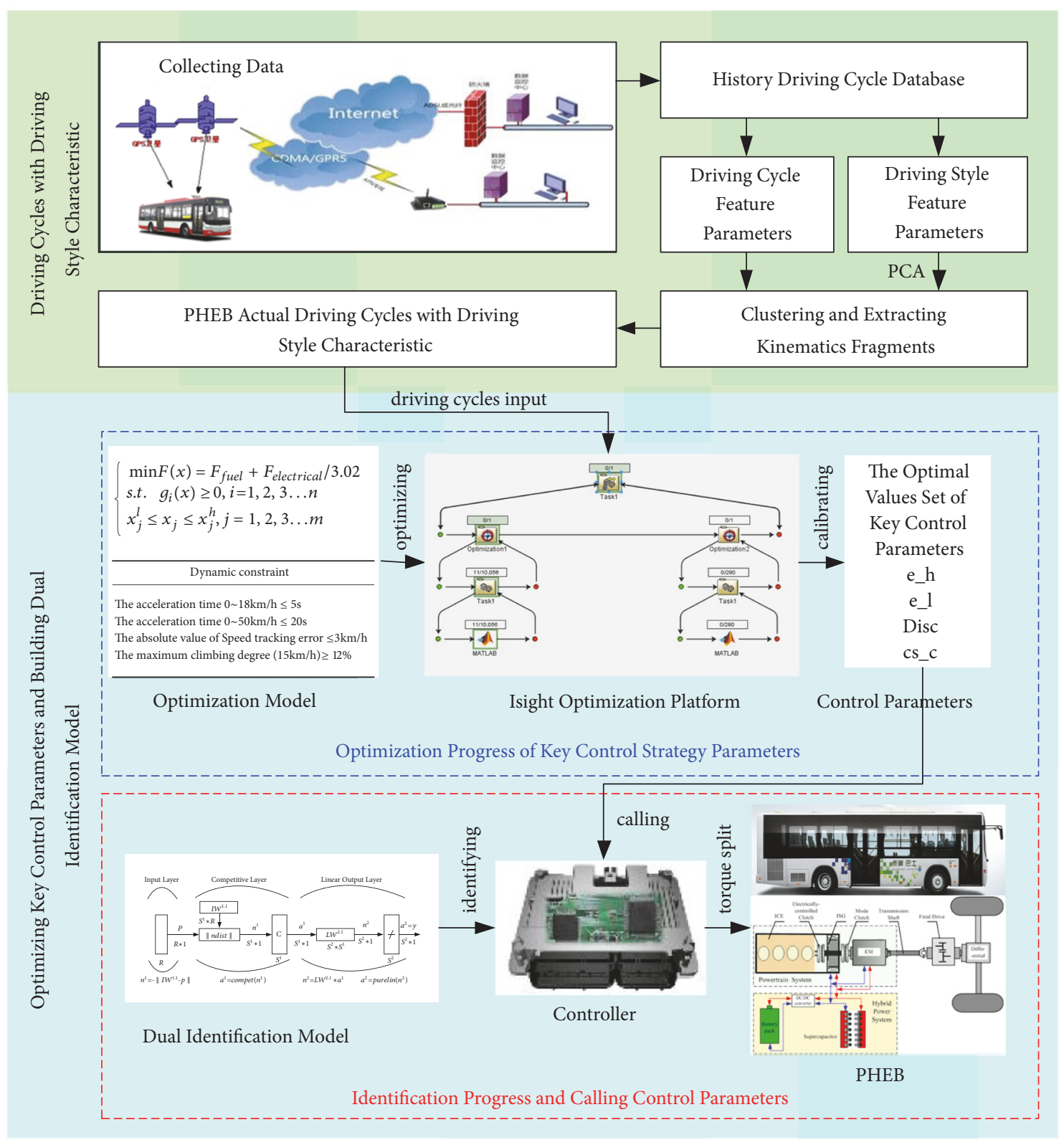

FIGURE 1: Structure schematic of this research.

take the driving cycles and driving styles into simultaneous consideration, and the economy of PHEB can be further improved. So it is of great significance to fit the actual driving cycles with driving style characteristic and then optimize the control strategy for PHEB to exert fully its comprehensive performance.

In this paper, a control strategy for PHEB based on actual driving cycle with driving style characteristic is proposed, as shown in Figure 1, mainly including the progress to fit out actual driving cycles with driving style characteristic and the progress to optimize the control strategy based on the above driving cycles. The structure of this paper is as follows. A large amount of city bus road driving data is collected in real time and divided into different types of driving cycles, and driving styles through different characteristic parameters by using PCA and CA, and then 6 actual driving cycles with driving style characteristic are fitted finally in Section 2. In Section 3, the key parameters of the control strategy are optimized by Isight automatic optimization platform by using a combinatorial optimization algorithm with the above actual driving cycles, and a control strategy for PHEB is built to invoke the corresponding optimized key control parameters in real time with a driving cycle identification model, which has been trained through PCA and LVQ neural network. A HIL test is designed to verify the validity and practicability of the control strategy for PHEB based on actual driving cycle with driving style characteristic in Section 4. Finally, Section 5 concludes the paper. 


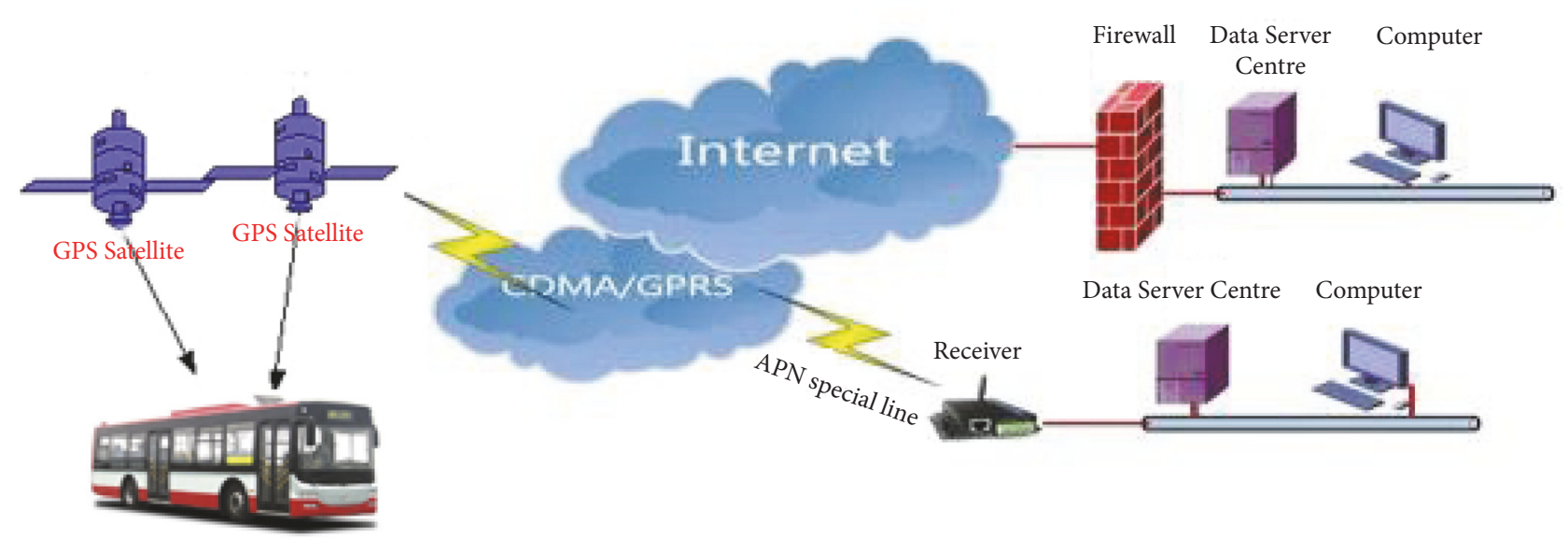

FIGURE 2: Schematic diagram of data acquisition process.

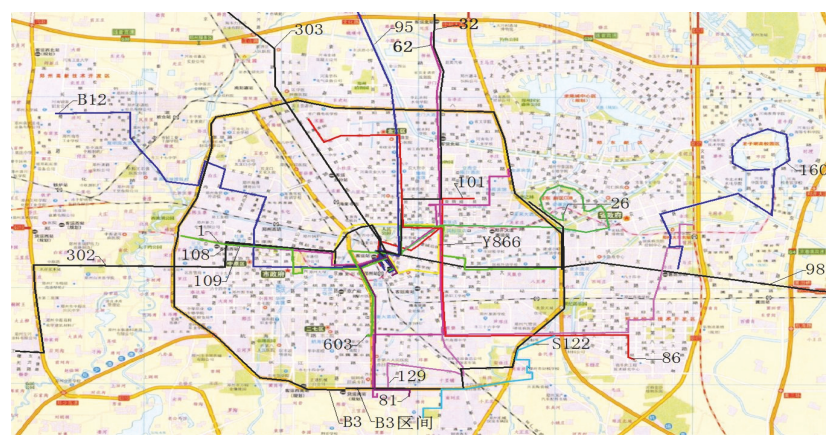

(a) Bus lines for data acquisition

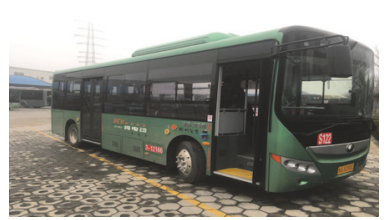

(b) A bus for data acquisition

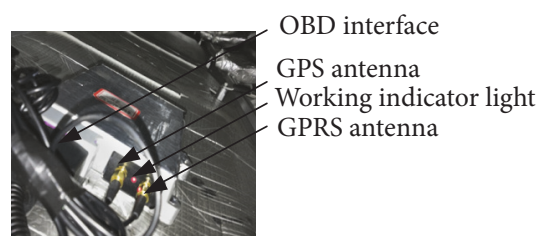

(c) Data acquisition equipment

FIgURE 3: Routes, bus, and equipment for data acquisition.

\section{Actual Driving Cycles with Driving Style Characteristic}

Combined with the traffic characteristics of city bus, the kinematic fragment analysis is usually served as the driving cycle development method and then through PCA and CA, and then some kinematics fragments with driving cycle and driving style characteristics will be selected to fit out the actual driving cycles with driving style characteristic $[9,10]$.

2.1. Data Acquisition and Preprocessing. The city bus driving data are acquired through China Automotive Test Cycles (CATC) information system, and the schematic of data acquisition is expounded in Figure 2.

Taking into consideration that the bus lines are fixed and the buses always run on different lines with different speeds, the bus lines can reflect the city bus driving characteristic to some extent, and the chosen bus lines are expounded in Figure 3(a), where the 21 bus lines covered the main road, the subtrunk road, the branch road, the loop line, and the outside area. And the bus type and the equipment, used in the data acquisition progress, are shown in Figures 3(b) and $3(\mathrm{c})$, respectively.

Through the vehicle terminal equipment, the city bus operating data is collected in real time. The preprocessing progress is the kinematic fragment analysis progress; that is, several characteristic parameters are extracted to represent the kinematic fragments. In this paper, a total of 20182 kinematic segments are used, and there are 12 characteristic parameters, as shown in Table 1, which are introduced to describe the characteristics of each kinematics fragment accurately and comprehensively. So the total actual driving 
TABLE 1: Kinematics segment features parameters.

\begin{tabular}{lcc}
\hline & description & unit \\
\hline$S_{o}$ & operating distance & $\mathrm{m}$ \\
$V_{\text {ave }}$ & average speed & $\mathrm{m} / \mathrm{s}$ \\
$V_{\text {max }}$ & maximum speed & $\mathrm{m} / \mathrm{s}$ \\
$T_{o}$ & operating time & $\mathrm{s}$ \\
$T_{i}$ & idle time & $\mathrm{s}$ \\
$T_{a}$ & acceleration time & $\mathrm{s}$ \\
$T_{d}$ & deceleration time & $\mathrm{s}$ \\
$T_{c}$ & constant time & $\mathrm{s}$ \\
$A_{\min }$ & minimum acceleration & $\mathrm{m} / \mathrm{s}^{2}$ \\
$A_{\text {max }}$ & maximum acceleration & $\mathrm{m} / \mathrm{s}^{2}$ \\
$A_{\text {a-ave }}$ & $\mathrm{m} / \mathrm{s}^{2}$ \\
$A_{d-\text { ave }}$ & average acceleration during acceleration time & $\mathrm{m} / \mathrm{s}^{2}$ \\
\hline
\end{tabular}

TABLE 2: Matrix X.

\begin{tabular}{lccccc}
\hline Segment & $S_{o}$ & $V_{\text {ave }}$ & $\ldots$ & $A_{\text {a-ave }}$ & $A_{\text {d-ave }}$ \\
\hline 1 & 29.528 & 0.615 & $\ldots$ & 0.575 & -0.783 \\
2 & 279.000 & 4.729 & $\ldots$ & 0.501 & -0.767 \\
3 & 145.139 & 4.682 & $\ldots$ & 0.632 & -1.333 \\
4 & 357.694 & 7.452 & $\ldots .580$ & -0.977 \\
5 & 375.944 & 6.163 & $\ldots$ & -0.789 \\
$\vdots$ & $\vdots$ & $\vdots$ & $\vdots$ & $\vdots$ \\
20179 & 339.639 & 5.959 & $\ldots$ & 0.647 & -0.557 \\
20180 & 184.389 & 2.459 & $\ldots$ & 0.453 \\
20181 & 506.583 & 4.967 & $\ldots$ & 0.514 & -0.513 \\
20182 & 339.639 & 5.959 & & -0.785 \\
\hline
\end{tabular}

sample data can be represented by a 20182 (sample size) $\times 12$ (eigenvalue) matrix, denoted as $\mathrm{X}$, as shown in Table 2.

2.2. PCA and CA. Although the 12 characteristic parameters can describe the kinematics fragment, there are some considerable differences in the influence extent. Therefore, the PCA is introduced to analyze influence extent of each characteristic parameter to simplify the following CA. Before PCA, to eliminate the different dimensions influence, the above matrix $\mathrm{X}$ needs to be standardized firstly. The matrix, after being standardized, is denoted as $\mathrm{Y}$, and the calculation method is

$$
\begin{aligned}
\bar{x}_{j} & =\frac{1}{n} \sum_{i=1}^{n} x_{i j} \\
s d_{j} & =\left[\frac{1}{n-1} \sum_{i=1}^{n}\left(x_{i j}-\bar{x}_{j}\right)^{2}\right]^{1 / 2} \\
y_{i j} & =\frac{x_{i j}-\bar{x}_{j}}{s t d_{j}}
\end{aligned}
$$

where $x_{i j}$ is the $j$ th characteristic parameter in $i$ th kinematics fragment, $\bar{x}_{j}$ is the mean of $j$ th characteristic parameter, $s d_{i}$ is the standard deviation of $j$ th characteristic parameter, and $n$ is the total number of kinematics fragments. Then the
PCA is conducted according to [11, 12]; if the cumulative contribution rate of the top several principal components can get to $80 \%$, it can be taken for granted that the top several principal components are retained. The result of PCA is shown in Table 3, and the cumulative contribution rate of the top 4 principal components has reached $83.767 \%$, which can be used to characterize the kinematic fragment. And the principal component score of each kinematic fragment, which can characterize the pertinence between principal components and kinematic fragment, is illustrated in Table 4.

To achieve ideal clustering effect, the optimal clustering number needs to be determined primarily. The optimal clustering number is determined by Calinski-Harabasz $(\mathrm{CH})$ index [13], which is as follows:

$$
C H(k)=\frac{(n-c) \operatorname{tr} A(k)}{(c-1) \operatorname{tr} D(k)}
$$

where $n$ is the clustering number, $c$ is the category of current driving cycle, $\operatorname{tr} D(k)$ is the trace of scatter matrix within the same driving cycle class, and $\operatorname{tr} A(k)$ is the trace of scatter matrix between different driving cycle classes. From Equation (2), a larger $\mathrm{CH}$ index represents a closer relation within the same class and a more dispersed relation between different classes. The $\mathrm{CH}$ index result is shown in Figure 4; the optimal clustering number is 3 , which are divided as congested, urban, and suburban, and the cluster centers are shown in Table 5. 
TABLE 3: Contribution rates of each principal component.

\begin{tabular}{lccc}
\hline Principal component & Characteristic value & Contribution rate /\% & Cumulative contribution rate /\% \\
\hline$M_{1}$ & 5.417 & 45.141 & 45.141 \\
$M_{2}$ & 2.390 & 19.913 & 65.054 \\
$M_{3}$ & 1.226 & 10.214 & 75.268 \\
$M_{4}$ & 1.020 & 8.499 & 83.767 \\
$\vdots$ & $\vdots$ & $\vdots$ & $\vdots$ \\
$M_{11}$ & 0.053 & 0.441 & 100.000 \\
$M_{12}$ & 0.000 & 0.000 & 100.000 \\
\hline
\end{tabular}

TABle 4: Principal component score matrix.

\begin{tabular}{lcccc}
\hline Kinematic fragment & $S_{1}$ & $S_{2}$ & $S_{3}$ & $S_{4}$ \\
\hline 1 & -3.5447 & 0.9675 & -0.5464 & -0.4286 \\
2 & -2.994 & 0.1830 & -0.8233 & 0.2899 \\
3 & -0.1708 & -0.3219 & -0.8605 & -0.2747 \\
$\vdots$ & $\vdots$ & $\vdots$ & $\vdots$ & $\vdots$ \\
20181 & 2.6977 & -0.1106 & -1.1680 & 0.0902 \\
20182 & 0.5675 & -0.6737 & 0.1363 & -0.5445 \\
\hline
\end{tabular}

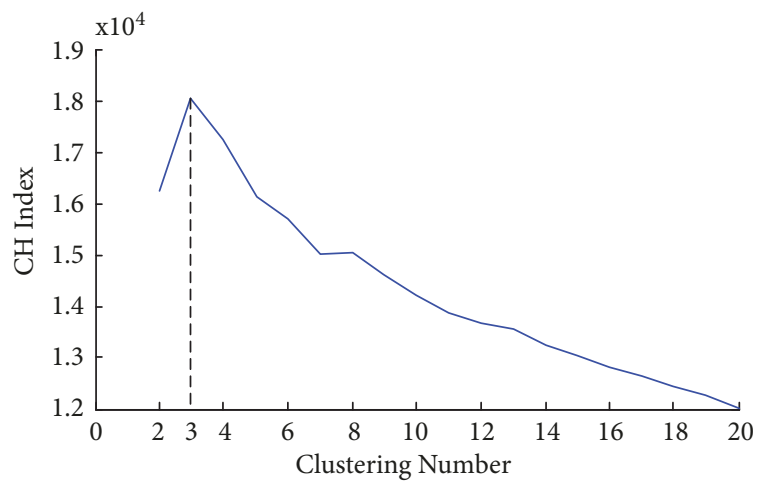

FIGURE 4: $\mathrm{CH}$ index of different clustering numbers.

The driving style characteristic is embodied in the fact that the energy consumption is often quite different under different driving styles when the same vehicles are in the same route and similar driving conditions. The average acceleration and the acceleration standard deviations are introduced to represent driving style characteristic, which can embody the driver's demand for power and the dispersion degree of the acceleration in the driving process [7]. Consider

$$
\begin{aligned}
\bar{a} & =\frac{1}{n} \sum_{i=1}^{n} a_{i} \\
s d(a) & =\left[\frac{1}{n-1} \sum_{i=1}^{n}\left(a_{i}-\bar{a}\right)^{2}\right]^{1 / 2}
\end{aligned}
$$

where $n$ is the sampling frequency, $a_{i}$ is the acceleration value at time $i$ corresponding to the fragment, and $a$ is the acceleration sampling value. 2 kinds of driving styles, economic and dynamic, are clustered by combining $\bar{a}$ and $s d(a)$ after the above driving cycle's CA, and the cluster centers are shown in Table 6.

2.3. Driving Cycle with Driving Style Characteristic. According to the Constant Volume Sampling (CVS) and the experience of fitting driving cycle, 6 driving cycles with driving style characteristic, of which the duration is about $1200 \mathrm{~s}$, are fitted out [14]. When selecting kinematics fragment, the Euclidean distance between the kinematics fragment and the cluster center is introduced; these kinematics fragments will be selected, which have the minimum sum of driving cycle Euclidean distance $\left(D_{D C-I J}\right)$ and driving cycle Euclidean distance $\left(D_{D S-I J}\right)$ between the Ith kinematics fragment and the cluster center of the Jth column that the kinematics fragment belongs to,

$$
\begin{aligned}
D_{I J} & =D_{D C \_I J}+D_{D S \_J} \\
D_{D C \_I J} & =\left[\left(S_{I, 1}-S_{1}^{J}\right)^{2}+\ldots+\left(S_{I, 4}-S_{4}^{J}\right)^{2}\right]^{1 / 2} \\
D_{D S \_I J} & =\left[\left(\bar{a}_{I}-\bar{a}^{J}\right)^{2}+\left(s d(a)_{I}-s d(a)^{J}\right)^{2}\right]^{1 / 2}
\end{aligned}
$$

where $S_{I, N}$ is the Nth principal component score of the Ith kinematics fragment, $S_{N}{ }^{J}$ is the $N$ th principal component score of the driving cycle cluster center, $N=4$ in this paper, $\bar{a}_{I}$ and $s d(a)_{I}$ are the average acceleration and the acceleration standard deviations of the Ith kinematics fragment, and $\bar{a}^{I}$ and $s d(a)^{J}$ are the driving style cluster center. What is more, in order to facilitate the vehicle to reproduce and follow the driving cycles well, it is necessary to smooth driving cycles that have been fitted. And Figure 5 shows the different kinds of city bus driving cycles under different driving styles after smooth filtering.

Considering that a certain identification time period in the following control strategy development is needed, it is 
TABLE 5: Principal component cluster centers.

\begin{tabular}{lcccc}
\hline Clusters & $S_{1}$ & $S_{2}$ & $S_{3}$ & $S_{4}$ \\
\hline congested & 2.9041 & 0.6295 & 0.0299 & 0.0814 \\
urban & -0.1245 & -1.0579 & -0.0974 & -0.0852 \\
suburban & -2.3031 & 0.9749 & 0.1137 & 0.0523 \\
\hline
\end{tabular}

TABLE 6: Driving style cluster centers in 3 driving cycles.

\begin{tabular}{lcr}
\hline Clusters & $\bar{a}$ & $s d(a)$ \\
\hline Congested-economic & 0.1248 & 0.2153 \\
Congested-dynamic & 0.3112 & 0.3856 \\
Urban-economic & 0.3598 & 0.4502 \\
Urban-dynamic & 0.5820 & 0.6421 \\
Suburban-economic & 0.2941 & 0.3356 \\
Suburban-dynamic & 0.4383 & 0.4790 \\
\hline
\end{tabular}

TABLE 7: Basic parameters of whole vehicle.

\begin{tabular}{lc}
\hline Symbol & Parameters \\
\hline Vehicle & Curb Weight: $12500 \mathrm{~kg}$, Gross Weight:18000 kg, Front Face Area: $6.6 \mathrm{~m}^{2}$, Air Resistance:0.55, Rolling Resistance: 0.018 \\
ICE & Nominal Power: $147 \mathrm{~kW}$ \\
ISG & Nominal Power: $80 \mathrm{~kW}$ \\
EM & Nominal Power: $144 \mathrm{~kW}$ \\
Battery pack & 121 Batteries (Nominal Voltage 3.8V, Nominal Capacity 30Ah) connected in series. \\
Supercapacitor & 8 Supercapacitors (Electrostatic Capacity: $145 \mathrm{~F}$, Nominal Voltage: $48 \mathrm{~V}$ ) are connected. \\
Final drive & Ratio: 6.17 \\
\hline
\end{tabular}

necessary to construct a comprehensive driving cycle to meet the parameter call in the recognition period. The duration scale of each driving cycle in comprehensive driving cycle is defined by the following:

$$
t_{i}=\frac{T_{i}}{T_{\text {overall }}} t_{d c}
$$

where $t_{i}$ is the duration of the cluster $i$ in comprehensive driving cycle, $T_{\text {overall }}$ is the duration of all kinematics fragments, $T_{i}$ is the duration of all kinematics fragments in cluster $i$, and $t_{d c}$ is the duration of the comprehensive driving cycle, about 1200s. The comprehensive driving cycle is shown in Figure 6, whose duration is 1174 s, including 273 s congested, 413 s urban, and 488 s suburban.

\section{PHEB Control Strategy Based on Driving Cycle with Driving Style Characteristic}

As is shown in Figure 7, the control strategy based on driving cycle with driving style characteristic is to add an identification module to recognize the current run condition and invoke the corresponding optimal control parameters to realize the adaptive effect of running in different conditions and driving styles. A particular point that needs to be explained is that the control strategy cannot identify the current condition in the first period; it will call the optimal control parameters of comprehensive driving cycle.
3.1. The Rule-Based Control Strategy. A $12 \mathrm{~m}$ single axis parallel-series PHEB is selected as the research object; the PHEB system configuration and main technical parameters are shown in Figure 8 and Table 7, respectively.

The rule-based control strategy is designed for the PHEB system, which is shown in Table 8 . The basic operation mode is divided into pure electric driving (PED), hybrid driving charge depleting (HDCD), and hybrid driving charge sustaining (HDCS) based on the battery SOC profile [15].

3.2. LVQ Neural Network Identification Model. The identification model is built to identify the driving cycles with driving style characteristic during the driving process. Although it is crucial to use more characteristic parameters for accurate identification, its complexity will be increased because these parameters are related to each other and have different dimensions. So an identification method is introduced by combining PCA with LVQ neural network according to [16]; the flow chart is shown in Figure 9.

Considering the impact of the identification period on identification effect, the identification accuracy has been nearly $90 \%$ within 120 s period in the actual driving condition, as shown in Figure 10, so that 120 s is selected as the identification period.

In order to prove the effectiveness and universality of the identification model, a comprehensive operating condition of the reacquisition of one month's bus driving condition data is 

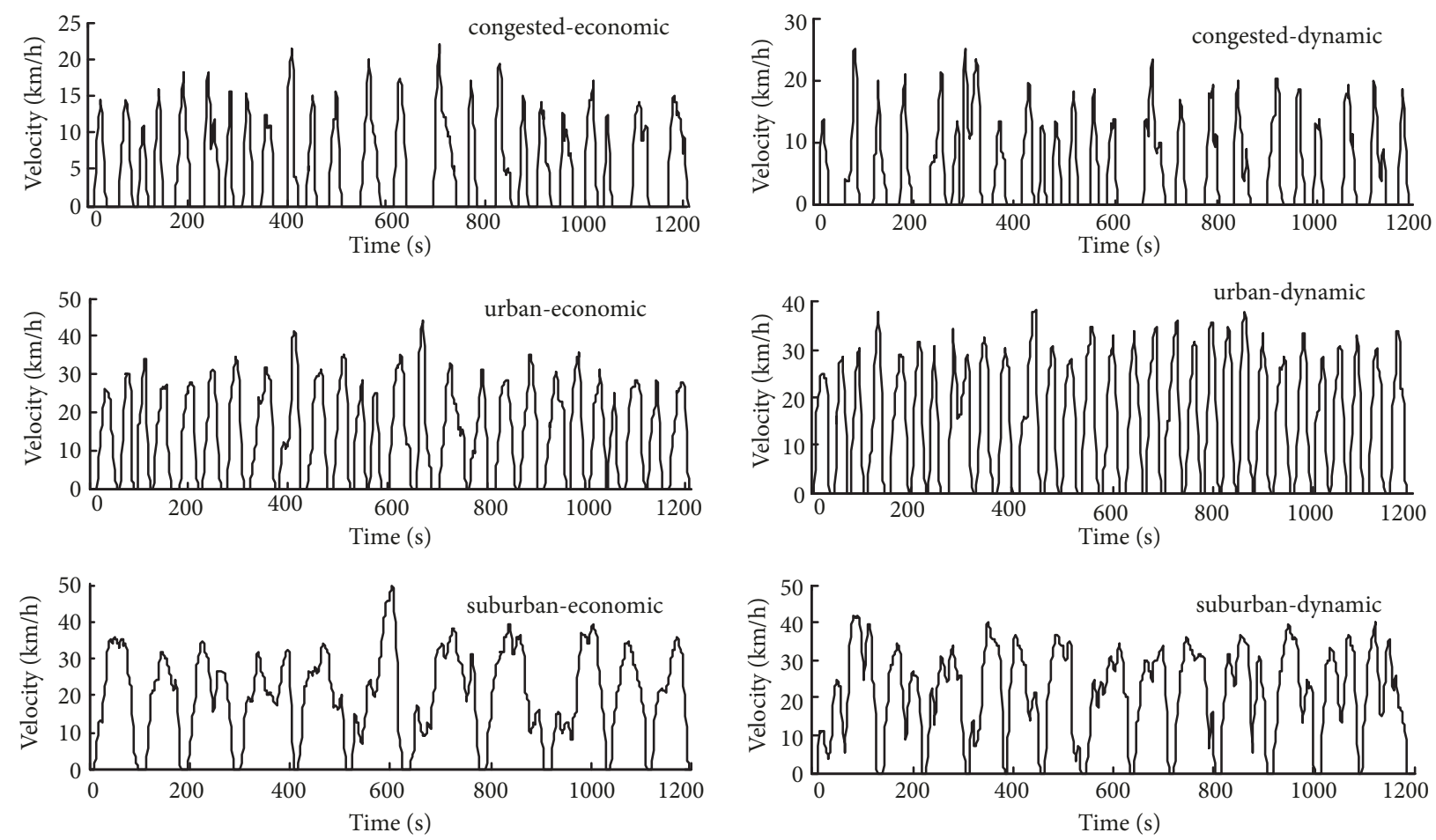

FIGURE 5: 6 actual driving cycles with driving style characteristic.

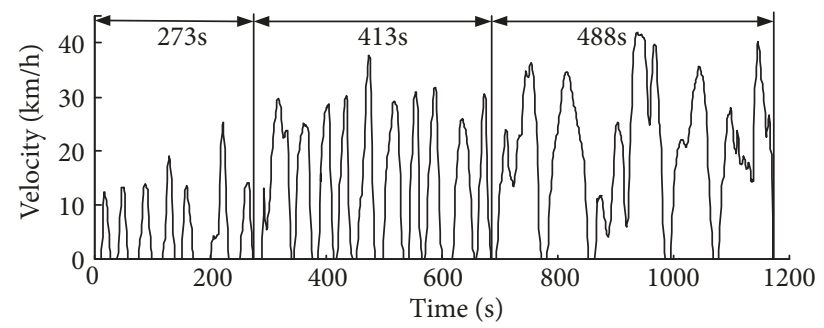

FIGURE 6: Comprehensive bus driving cycle.

constructed as the testing driving cycle, which lasts 1324s; the recognition result is shown in Figure 11.

From Figure 11, '1, '2,' '3,' '4,' '5', and '6' represent congested-economic, congested-dynamic, urban-economic, urban-dynamic, suburban-economic, and suburbandynamic, respectively. In the first 120 s period, the driving cycle series is identified as ' 0 '; that is to say, there are no identification result, because the period cannot satisfy the dual identification model. The rest period identification results are in line with the trend of velocity change and can reflect the driving cycle and driving style relatively more accurately and stably.

3.3. Key Control Parameters Optimization. The optimization parameters mathematical model is

$$
\min F(x)=F_{\text {fuel }}+\frac{F_{\text {electrical }}}{3.02}
$$

$$
\begin{array}{ll}
\text { s.t. } & g_{i}(x) \geq 0, \quad i=1,2,3 \ldots n \\
& x_{j}^{l} \leq x_{j} \leq x_{j}^{h}, \quad j=1,2,3 \ldots m
\end{array}
$$

where the $F(x)$ is the objective function of the optimization question, $F_{\text {fuel }}, F_{\text {electrical }}$ are, respectively, fuel and electrical consumption per $100 \mathrm{~km}, g_{i}(x) \geq 0$ is the dynamic constraint, $n$ is the number of constraints, $x_{j}$ are the key control strategy parameters, $x_{j}^{i}, x_{j}^{h}$ are, respectively, the range value set of each variable, and $m$ is the number of variable. The key control parameters and the constraints are introduced in Table 9.

The PHEB model built in AVL-Cruise and the control strategy built in MATLAB/Simulink are integrated in the Isight automatic optimization platform, illustrated in Figure 12. The key control parameters are optimized by using a compositional optimization algorithm, Multi-island Genetic Algorithm (MIGA), and Sequential Quadratic Programming (SQP) Algorithm.

The optimal key control parameters values of the above driving cycles with driving style characteristic are shown in Table 10. From Table 10, there is a large distinction in different driving cycles, which will improve the vehicle's robustness and adaptability to complicated work conditions.

\section{Hardware-in-the-Loop Test}

To verify the validity and practicability of the control strategy proposed in this paper, a HIL test is introduced, as is shown in Figure 13. The HIL test platform consists of a hardware system and a software system, where the hardware system 


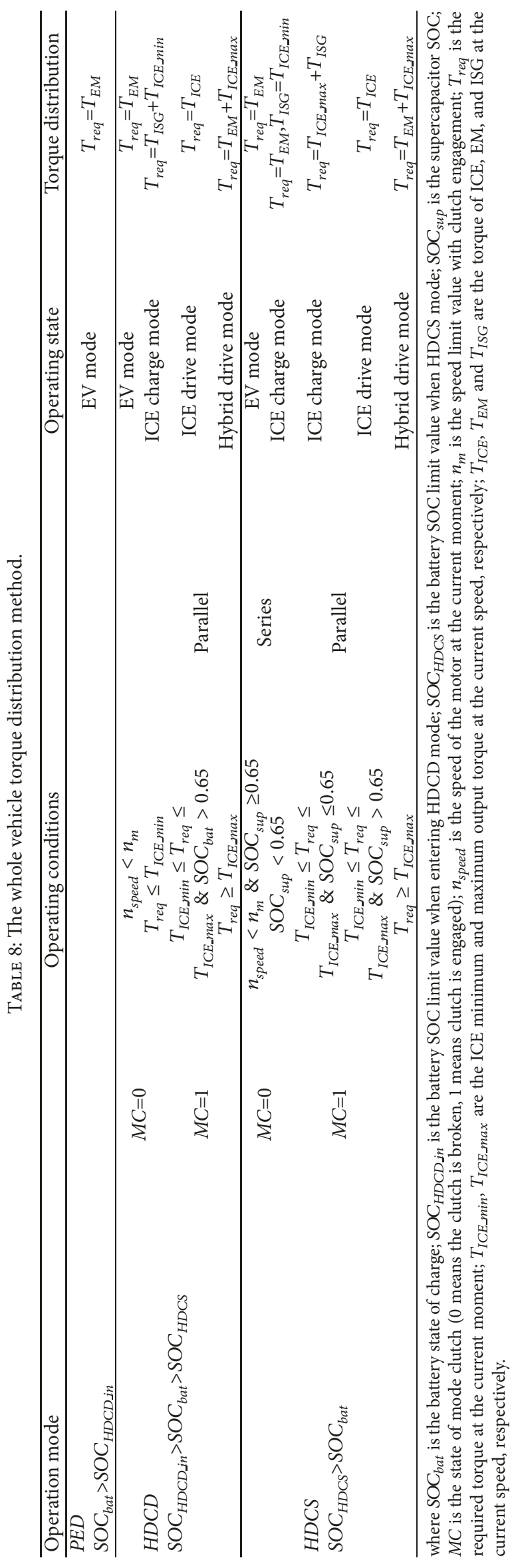




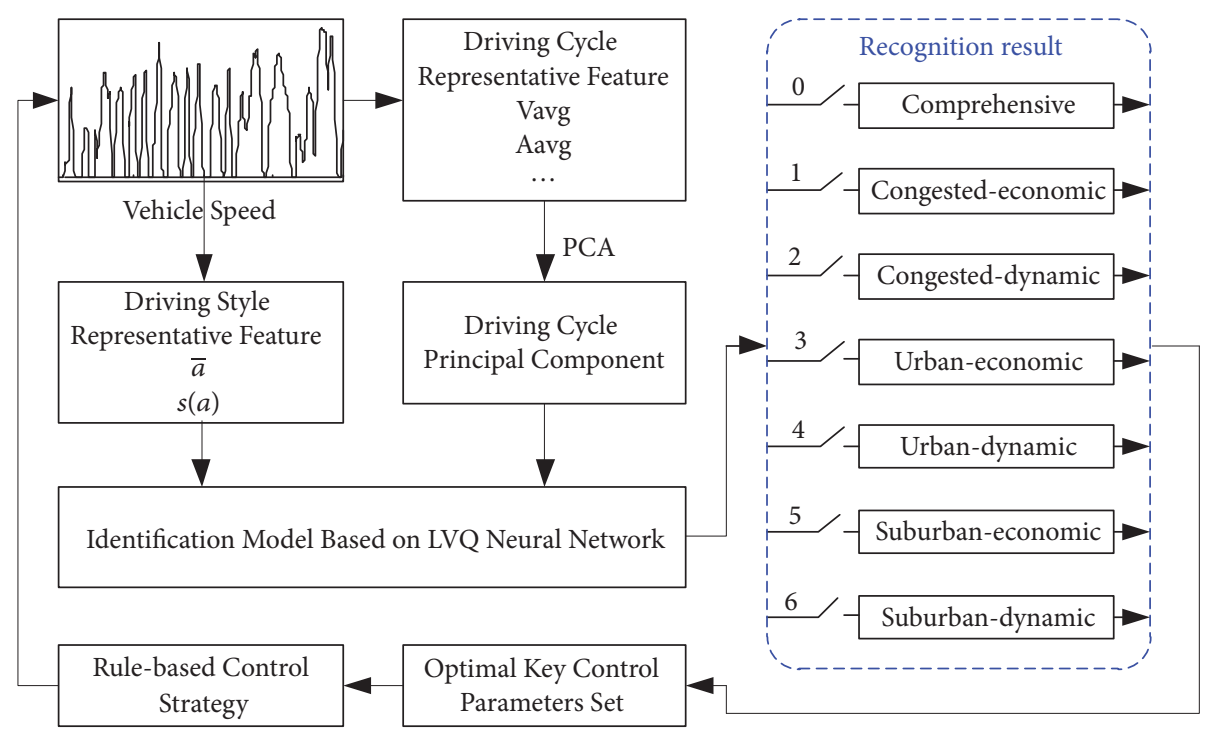

Figure 7: Control strategy based on dual identification.

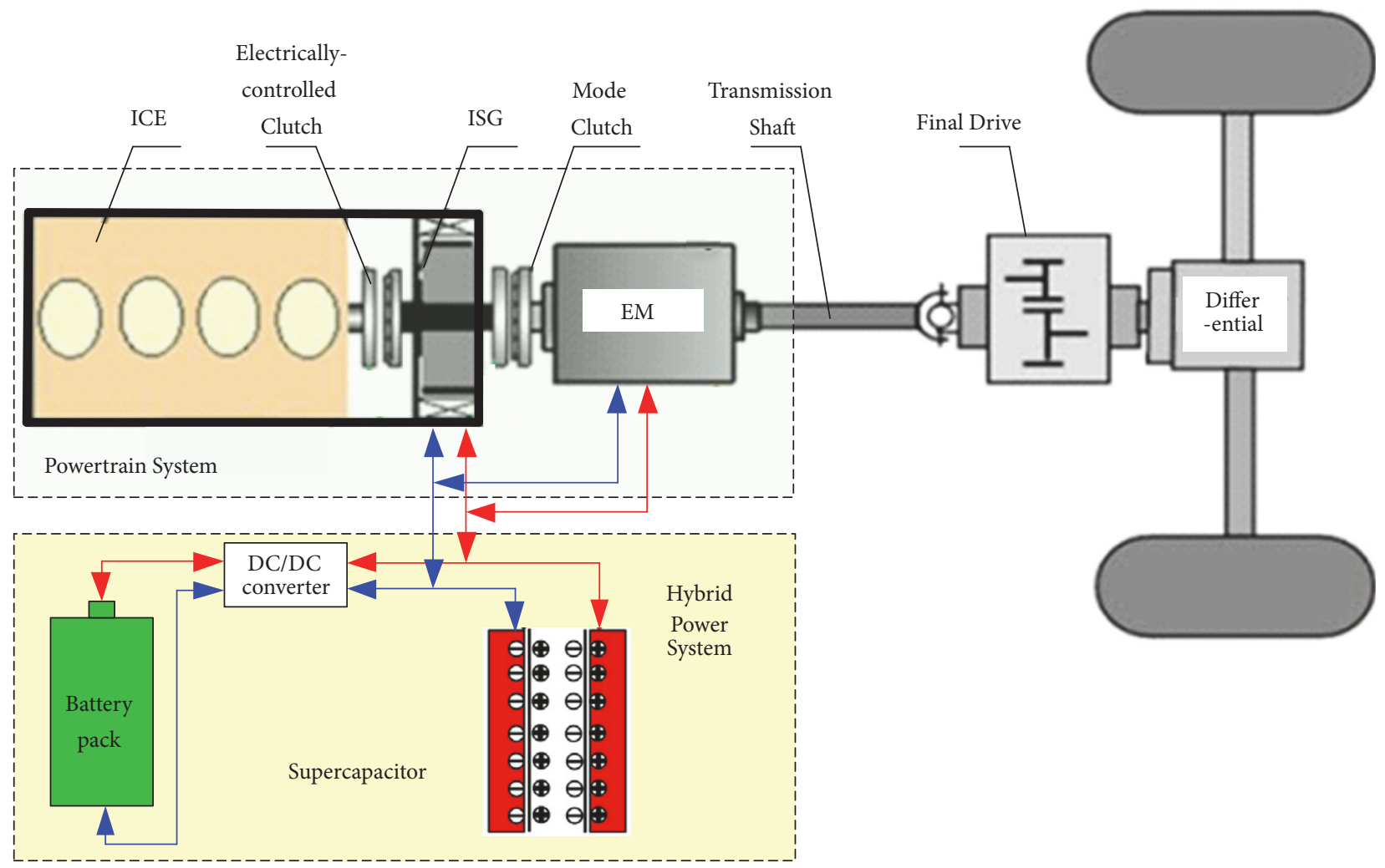

FIgURE 8: The configuration of the single axis parallel-series system.

mainly includes dSPACE, driving simulator, and CANoe, and the software system mainly includes AVL-Cruise, MATLAB/Simulink, and Controldesk.

The test results are shown in Figures 14-16. It can be seen from Figure 14 that the driver has completed the speed tracking well, which indicates that the control strategy meets the vehicle's dynamic performance requirements.
The SOC changes in battery and supercapacitor of the control strategy proposed in this paper and the rule-based control strategy at CS stage is shown in Figure 15; it can be seen that the supercapacitor SOC change in the strategy based on actual driving cycle with driving style characteristic has a large fluctuation, which will bring the supercapacitor characteristic, charging, and discharging in large current, into 


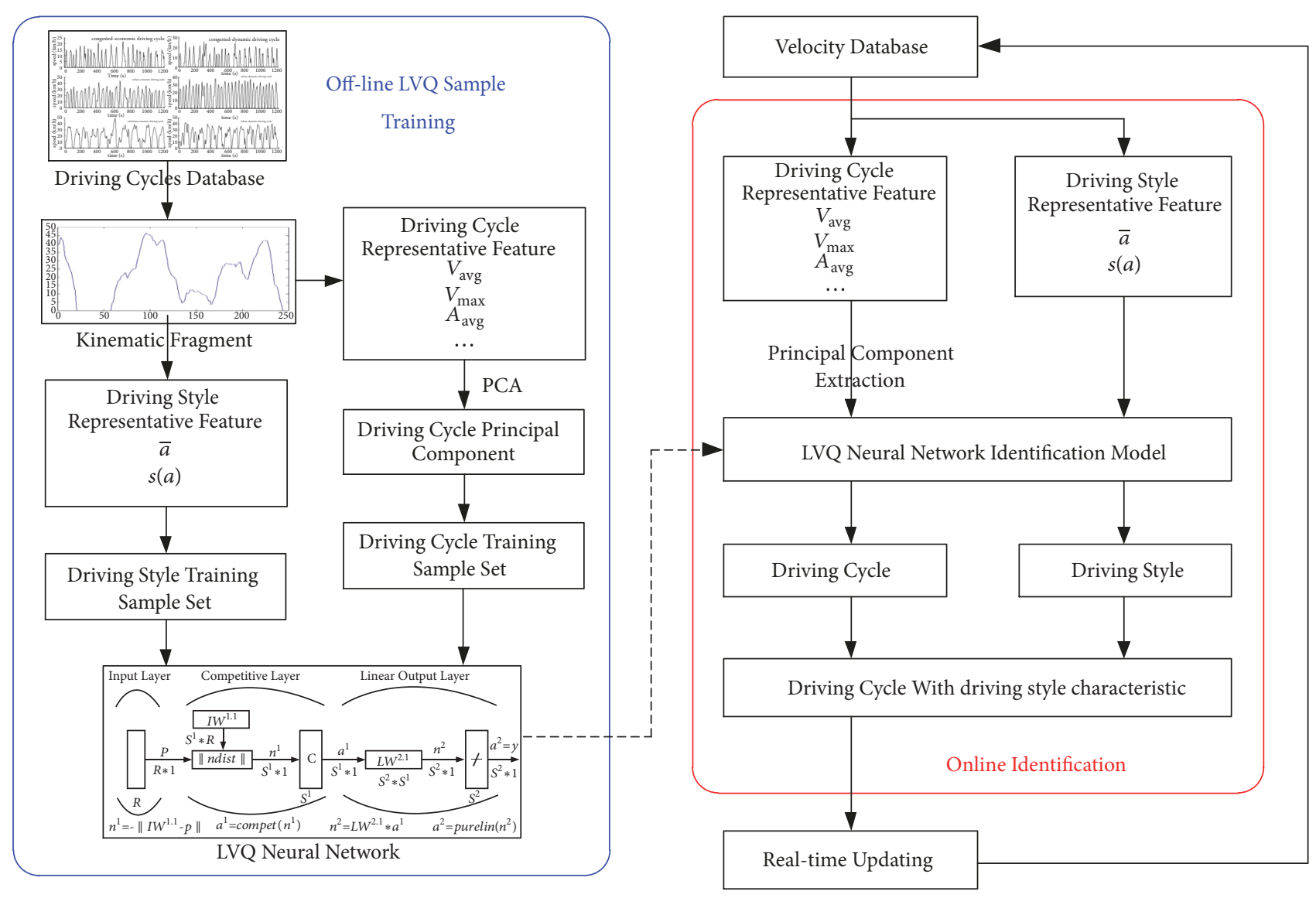

Figure 9: Flow chart of working condition identification.

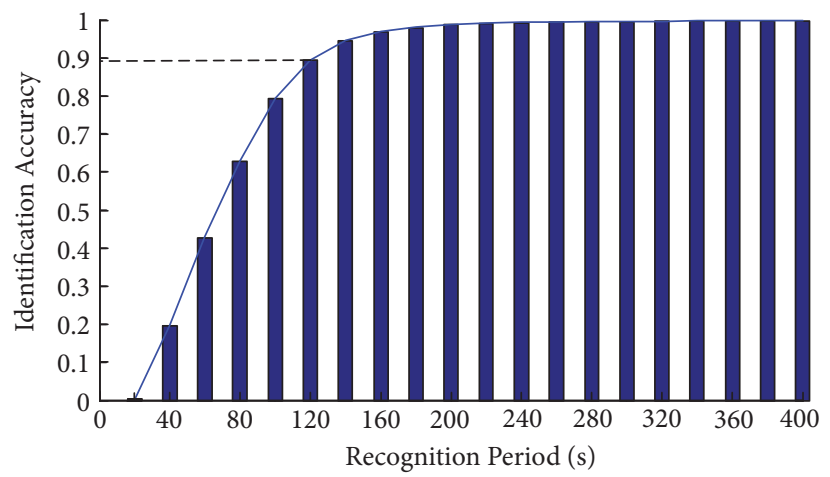

FIGURE 10: The identification accuracy in different identification periods.

TABLE 9: Optimization parameters and conditions.

\begin{tabular}{lccc}
\hline Optimization algorithm & Dynamic constraint & Optimization variables & Optimization object \\
\hline & $T_{a 0 \sim 18} \leq 5 \mathrm{~s}$ & $e \_h$ & min $F(x)$ \\
Combined optimization algorithm & $T_{a 0 \sim 50} \leq 20 \mathrm{~s}$ & $e_{-}$ & disc \\
& $E_{v t} \leq 3 \mathrm{~km} / \mathrm{h}$ & $c s_{-} c$ & \\
\hline
\end{tabular}

where $T_{a 0 \sim 18}$ is the acceleration time $(0 \sim 18 \mathrm{~km} / \mathrm{h}) ; T_{a 0 \sim 50}$ is the acceleration time $(0 \sim 50 \mathrm{~km} / \mathrm{h}) ; E_{v t}$ is the absolute value of speed tracking error; $G_{a 15}$ is the maximum gradeability $(15 \mathrm{~km} / \mathrm{h}) ; e \_h, e \_l$ are the correction coefficients of ICE working upper limit and lower limit, respectively; disc is the discharge coefficient of the supercapacitor; $c s_{-} c$ is the joint speed of mode clutch at CS stage. 


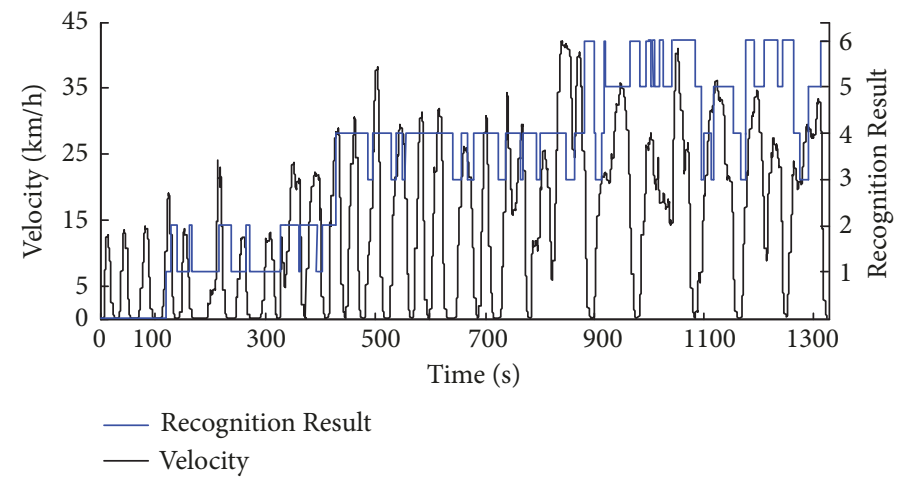

FIGURE 11: Recognition result of dual identification.

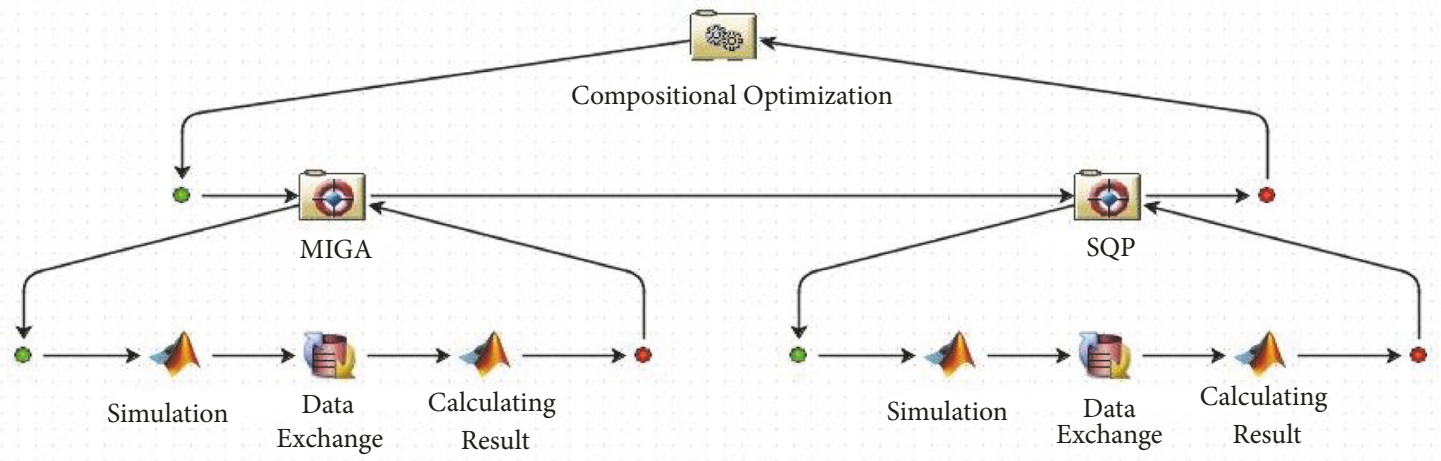

FIGURE 12: Isight automatic optimization platform.

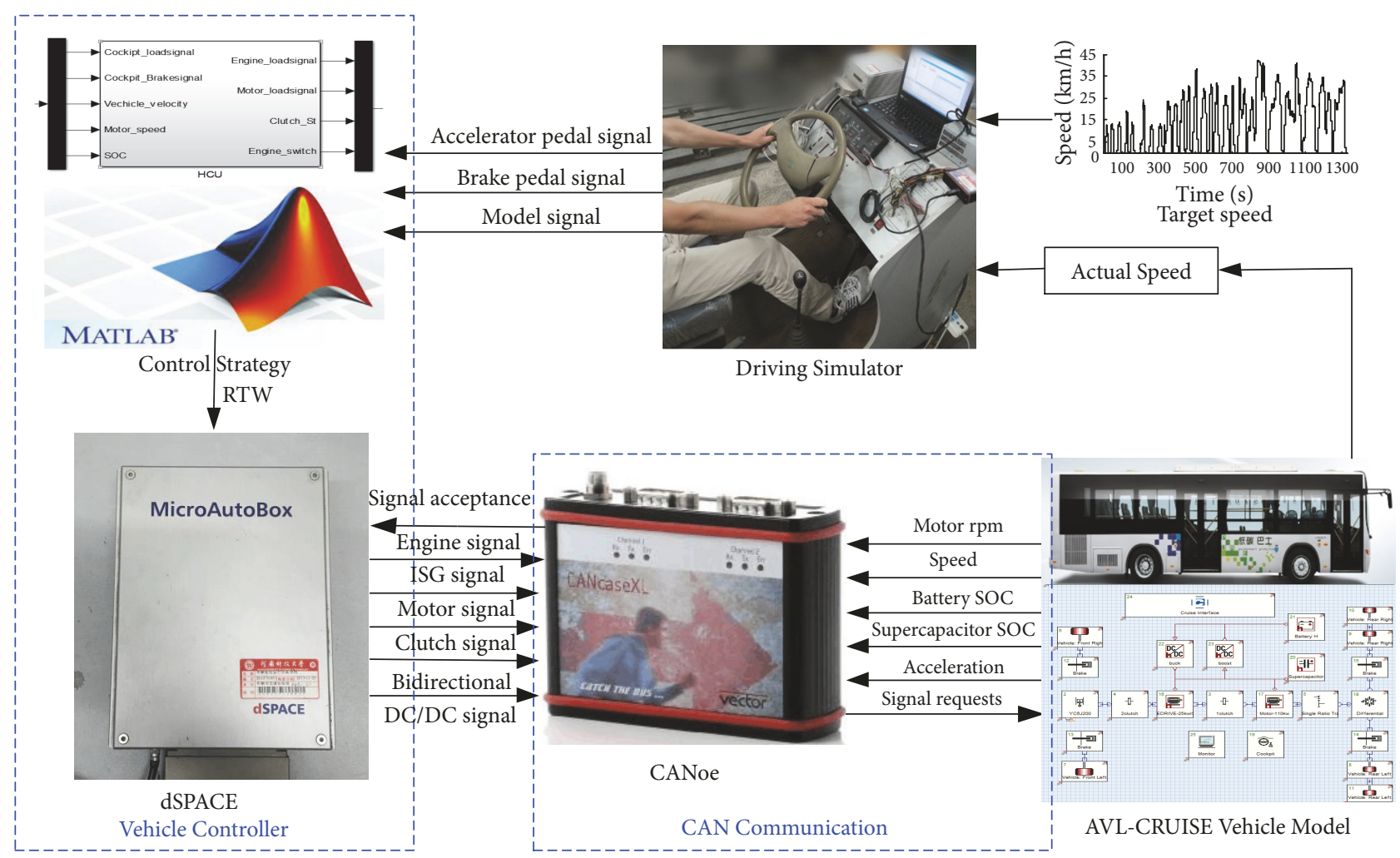

FIGURE 13: HIL simulation test scheme. 


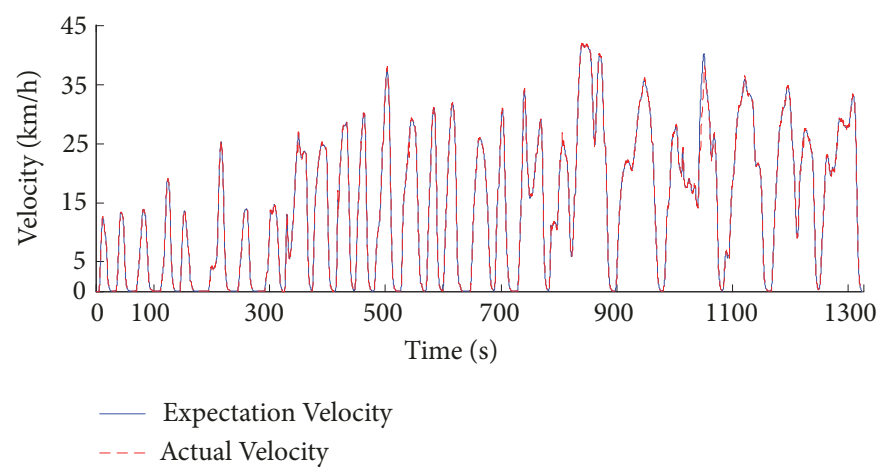

FIgURE 14: Comparison of speed tracking curve.

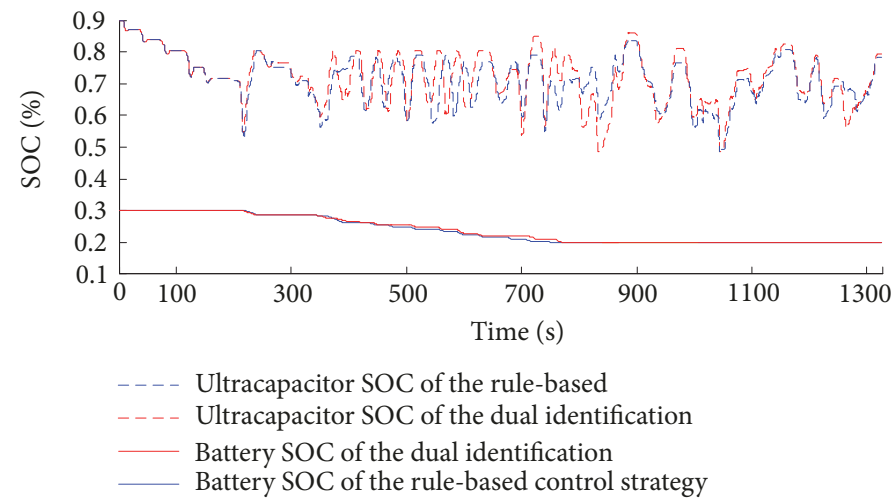

FIGURE 15: SOC of the hybrid power system at CS phase.

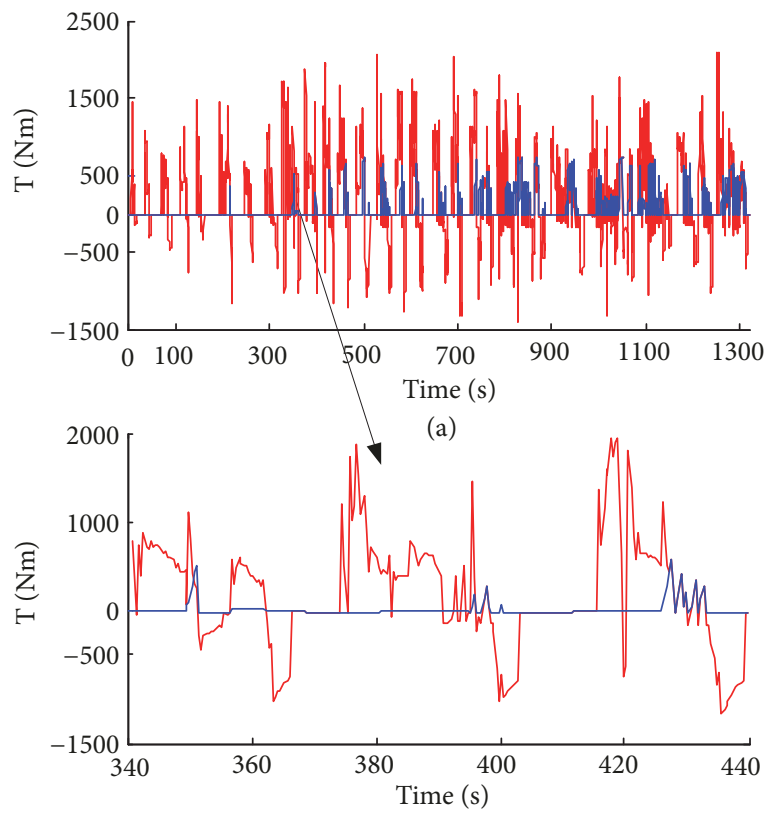

(b)
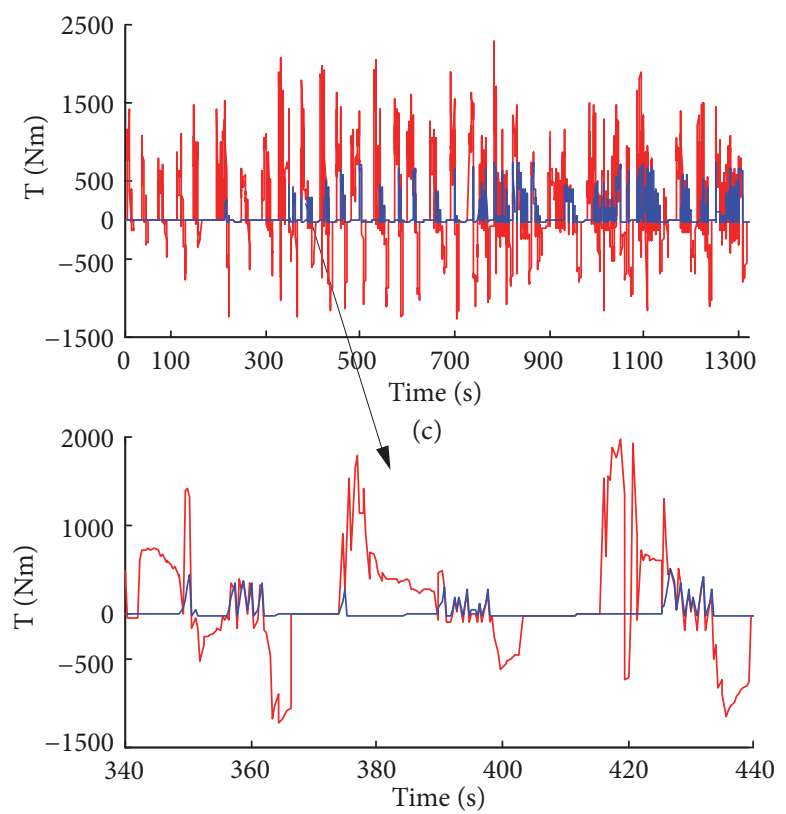

(d)

— Demand Torque —— Actual Engine Torque

Figure 16: Demand torque and ICE torque of two strategies. 
TABLE 10: The change of vehicle control strategy parameters before and after the optimization of various conditions.

\begin{tabular}{lcccccccc}
\hline \multirow{2}{*}{ Optimization variables } & \multirow{2}{*}{ Before } & \multicolumn{2}{c}{ Congested } & \multicolumn{2}{c}{ Urban } & \multicolumn{3}{c}{ Suburban } \\
& & Economic & Dynamic & Economic & Dynamic & Economic & Dynamic & Comprehensive \\
\hline cs_c (r/min) & 630 & 650.42 & 694.93 & 608.33 & 603.74 & 677.95 & 646.69 & 682.91 \\
disc & 0.86 & 1.277 & 1.510 & 1.794 & 1.869 & 0.937 & 1.028 & 1.875 \\
e_h & 0.96 & 0.680 & 0.980 & 0.739 & 0.863 & 0.917 & 0.958 & 0.939 \\
e_l & 0.15 & 0.184 & 0.129 & 1.142 & 1.469 & 1.192 & 0.733 & 1.489 \\
\hline
\end{tabular}

TABLE 11: Energy comparison of hardware in the loop test.

\begin{tabular}{lcc}
\hline & This Paper & Rule-based \\
\hline Fuel $(\mathrm{L} / 100 \mathrm{~km})$ & 16.23 & 17.81 \\
Electricity $(\mathrm{kWh} / 100 \mathrm{~km})$ & 17.22 & 18.31 \\
Comprehensive Energy $(\mathrm{L} / 100 \mathrm{~km})$ & 22.13 & 23.28 \\
Reduction Ratio & & $4.94 \%$ \\
\hline
\end{tabular}

full play, and the battery SOC changes down more slowly. That is, the control strategy proposed in this paper can function better than the electric energy utilization efficiency of the hybrid power system.

As shown in Figure 16, (a) (c) are, respectively, the torque distribution diagram of the control strategy proposed in this paper and the rule-based control strategy, and (b) (d) are, respectively, the partially enlarged diagram from 340 s to 440 s of (a) (c). From (b) (d), it can be seen that the working time and frequency of ICE are significantly reduced using the control strategy proposed in this paper, which makes the EM more involved to drive the whole vehicle, when it is in the inefficient working area of the ICE, and thus reduces the comprehensive energy consumption.

In the test progress, the fuel and electricity consumption are obtained by the integral at different moments and converted into the consumption of $100 \mathrm{~km}$. In addition, the electricity consumption is converted into fuel consumption by Equation (6), and the sum of fuel and electricity is as the comprehensive energy consumption. The result is shown in Table 11; the proposed control strategy could improve the energy consumption by $4.94 \%$ compared with the original rule-based control strategy, and its validity and practicability are verified.

\section{Conclusions}

Using the city bus data collected in real time, through PCA and CA methods, the optimal number of driving cycles to cluster is determined by $\mathrm{CH}$ index, and the 6 typical bus driving cycles with the driving style characteristic. Through the Isight automatic optimization platform, the key control parameters are optimized by taking advantage of the 6 driving cycles with driving style characteristic. And an identification model for driving cycle with driving style characteristic is established to invoke the corresponding optimized key control parameters in real time.

Through the HIL test, the energy economy of the control strategy in this paper is improved by $4.94 \%$, compared with the rule-based control strategy, which proves that the control strategy can better improve the torque distribution between ICE and EM.

\section{Data Availability}

The data used to support the findings of this study are available from the corresponding author upon request.

\section{Conflicts of Interest}

The authors declare that there are no conflicts of interest regarding the publication of this paper.

\section{Acknowledgments}

This study is supported by the National Key R\&D Program in China (Grant no. 2018YFB0105904).

\section{References}

[1] Y. Huang, H. Wang, A. Khajepour, H. He, and J. Ji, "Model predictive control power management strategies for HEVs: A review," Journal of Power Sources, vol. 341, pp. 91-106, 2017.

[2] C. Yang, S. Du, L. Li, S. You, Y. Yang, and Y. Zhao, "Adaptive realtime optimal energy management strategy based on equivalent factors optimization for plug-in hybrid electric vehicle," Applied Energy, vol. 203, pp. 883-896, 2017.

[3] H. Lim and W. Su, "Hierarchical energy management for powersplit plug-in hevs using distance-based optimized speed and soc profiles," IEEE Transactions on Vehicular Technology, vol. 67, no. 10, pp. 9312-9323, 2018.

[4] H. Liu, X. Li, W. Wang, L. Han, and C. Xiang, "Markov velocity predictor and radial basis function neural network-based realtime energy management strategy for plug-in hybrid electric vehicles," Energy, vol. 152, pp. 427-444, 2018.

[5] S. Zhang, R. Xiong, and F. Sun, "Model predictive control for power management in a plug-in hybrid electric vehicle with a hybrid energy storage system," Applied Energy, vol. 185, pp. 1654-1662, 2017. 
[6] Y. Wang, W. Wang, Y. Zhao, L. Yang, and W. Chen, "A fuzzylogic power management strategy based on Markov random prediction for hybrid energy storage systems," Energies, vol. 9, no. 1, 2016.

[7] Q.-N. Wang, X.-Z. Tang, P.-Y. Wang, and L. Sun, "Control strategy of hybrid electric vehicle based on driving intention identification," Journal of Jilin University (Engineering and Technology Edition), vol. 42, no. 4, pp. 789-795, 2012.

[8] L. Li, S. You, C. Yang, B. Yan, J. Song, and Z. Chen, "Drivingbehavior-aware stochastic model predictive control for plugin hybrid electric buses," Applied Energy, vol. 162, pp. 868-879, 2016.

[9] G. A. O. Jian-ping, "Development of vehicle driving cycle and accuracy of research," Journal of ZheJiang University (Engineering Science), vol. 51, no. 10, pp. 2046-2054, 2017.

[10] J. Gao, Z. Sun, and L. Zhang, "Plug-in hybrid electric bus variable parameter control strategy considering influence of driving cycle," Journal of Xian Jiaotong University, vol. 51, pp. 130-139, 2017.

[11] Z. Wang, C. Wen, X. Xu, and S. Ji, "Fault diagnosis method based on gap metric data preprocessing and principal component analysis," Journal of Control Science and Engineering, vol. 2018, 2018.

[12] P. Tao, X. Feng, and C. Wen, "Image recognition based on two-dimensional principal component analysis combining with wavelet theory and frame theory," Journal of Control Science and Engineering, vol. 2018, 2018.

[13] R. Baragona, F. Battaglia, and I. Poli, Evolutionary Statistical Procedures: An Evolutionary Computation Approach to Statistical Procedures Designs And Applications, Springer Science \& Business Media, 2011.

[14] D.-T. Qin, S. Zhan, Z.-G. Qi, and S.-J. Chen, "Driving cycle construction using K-means clustering method," Journal of Jilin University (Engineering and Technology Edition), vol. 46, no. 2, pp. 383-389, 2016.

[15] X. Wang, H. He, F. Sun, X. Sun, and H. Tang, "Comparative study on different energy management strategies for plug-in hybrid electric vehicles," Energies, vol. 6, no. 11, pp. 5656-5675, 2013.

[16] H. He, C. Sun, and X. Zhang, "A method for identification of driving patterns in hybrid electric vehicles based on a LVQ neural network," Energies, vol. 5, no. 9, pp. 3363-3380, 2012. 


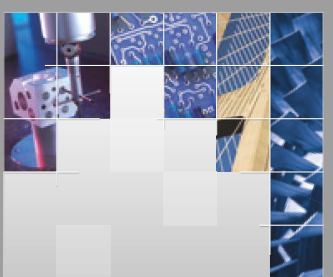

\section{Enfincering}
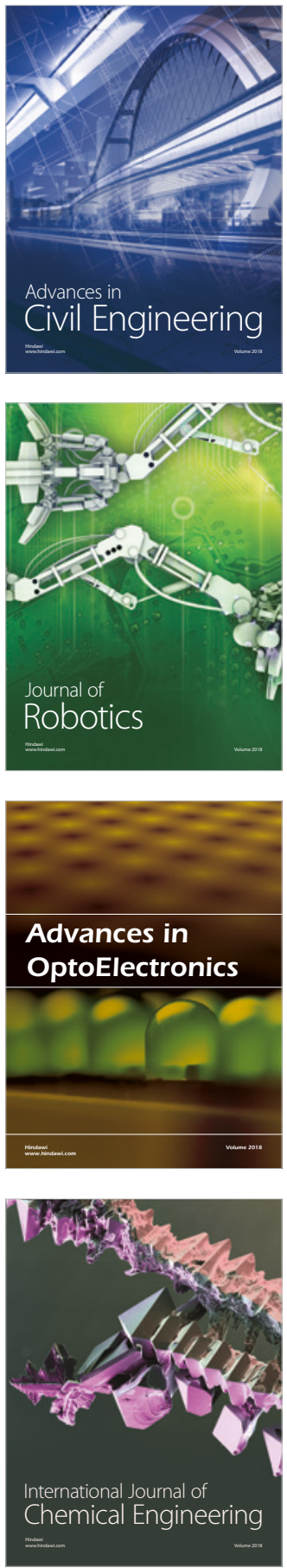

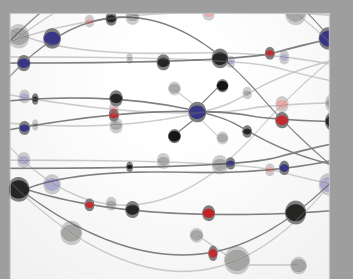

\section{Rotating \\ Machinery}

The Scientific World Journal

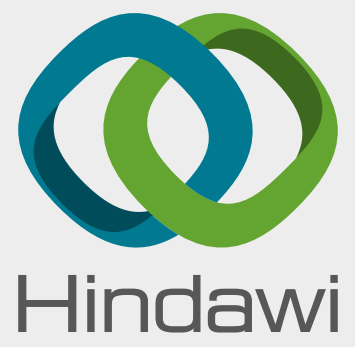

Submit your manuscripts at

www.hindawi.com
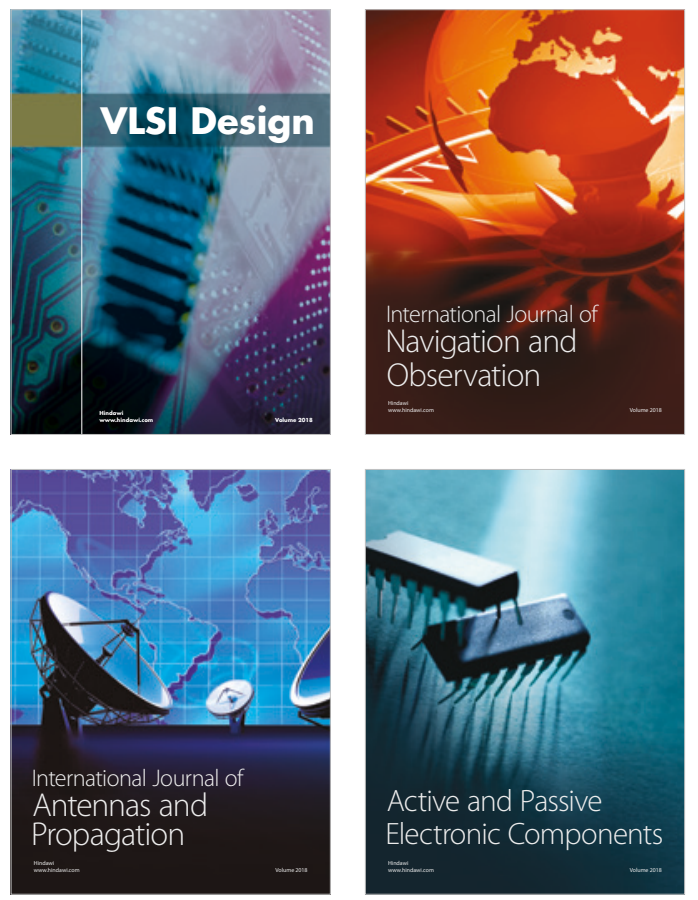
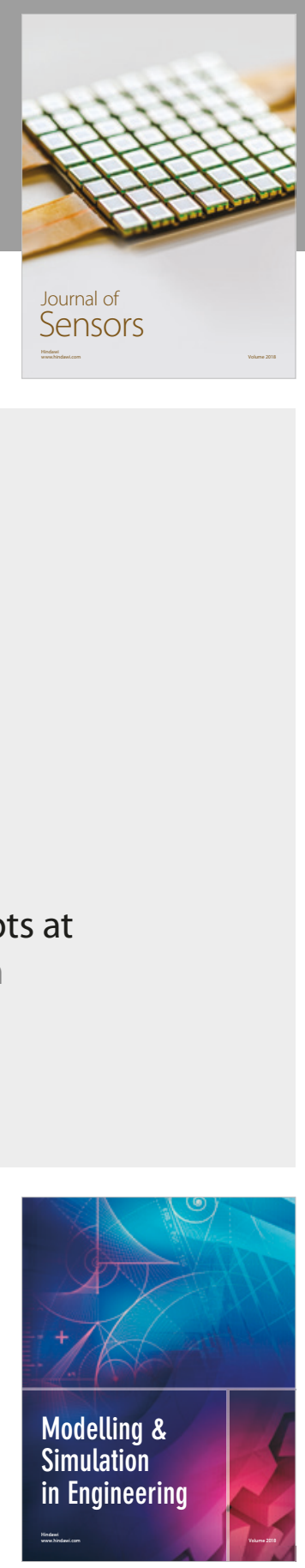

\section{Advances \\ Multimedia}
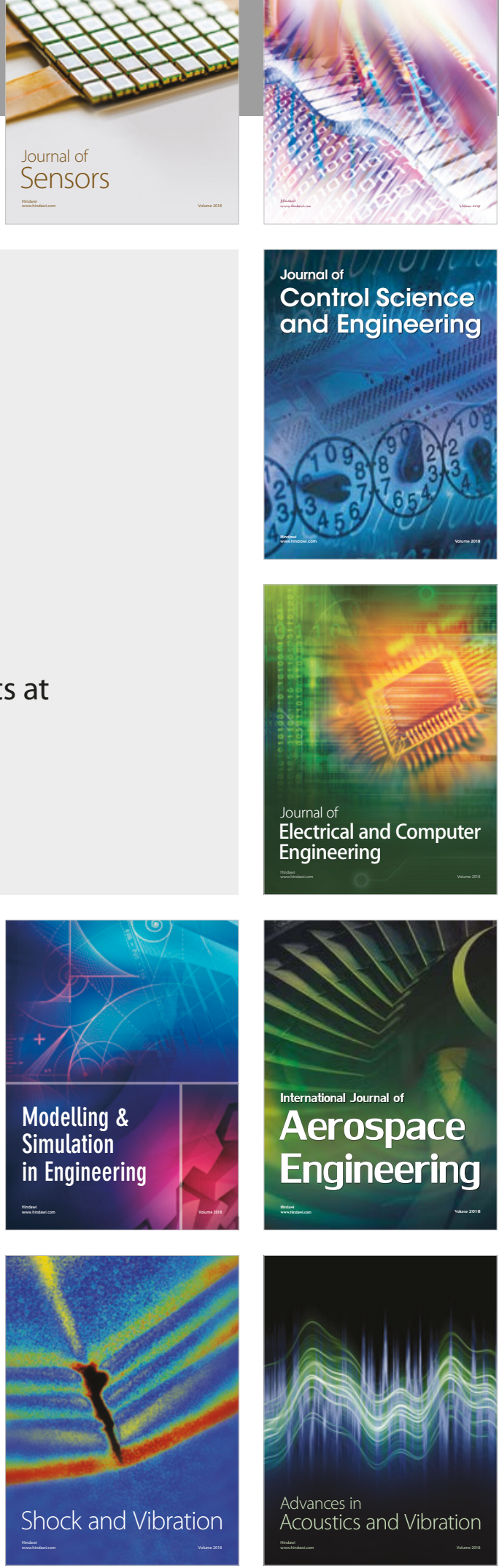